\title{
Relative Price Changes and the Optimal Inflation Rate
}

Alexander L. Wolman

$\mathrm{R}$ elative prices of some goods or sectors have long-run trends: For example, the price of services relative to goods has been rising fairly steadily for decades. Other relative prices do not have long-run trends but sometimes fluctuate dramatically from one period to the next: For example, the relative price of the energy goods and services component of personal consumption expenditures fell by approximately 22 percent from January 2014 to January 2015. Although monetary policy changes can affect relative prices, in most cases trends in relative prices and dramatic monthly fluctuations in relative prices seem best viewed as exogenous factors with respect to monetary policy. How should monetary policy behave in the face of these fluctuations? More precisely, how is the optimal rate of inflation affected by exogenous relative price fluctuations? The answer, of course, depends on many factors, not least of which are the sources of monetary non-neutrality. We focus here on costly price adjustment as the principal source of non-neutrality. We use a two-good macroeconomic model with costly price adjustment to study the optimal constant inflation rate when there are trends in relative prices. For the purpose of studying short-run fluctuations in relative prices, we take an informal empirical approach, using one part of the model to construct hypothetical U.S. inflation rates that would have minimized the costs of price adjustment implied by the model. We also consider the potential conflict between minimizing the costs of price adjustment and meeting the central bank's announced inflation target.

The topic of relative price changes and optimal inflation has received much attention from researchers. In the New Keynesian litera-

The views expressed here are those of the authors and not necessarily those of the Federal Reserve Bank of Richmond or the Federal Reserve System.

E-mail: Alexander.Wolman@rich.frb.org.

DOI: http://doi.org/10.21144/eq1010303 
ture, Aoki (2001) was an important early paper that made the point that goods with flexible prices should bear the burden of relative price adjustment. Aoki provides an argument for stabilizing core inflation related to the part of this paper that studies short-run relative price fluctuations. Bodenstein, Erceg, and Guerrieri (2008) is a related contribution. Neither Aoki nor Bodenstein, Erceg, and Guerrieri consider the effects of trend changes in relative prices, whereas Wolman (2008) provides an overview of this issue, and Wolman (2011) goes into more detail using models with staggered price setting and fixed costs of price adjustment. None of these previous papers construct historical time series for optimal inflation as a function of observable relative price changes, as we do in Section 5.

Both Aoki and Bodenstein use the Calvo price-adjustment framework, and Wolman (2011) also uses models with infrequent price adjustment. In contrast, this paper uses the Rotemberg model. An important factor in choosing Rotemberg instead of Calvo pricing is my desire to examine the implications of costly price adjustment, rather than infrequent price adjustment, for the optimal inflation rate. Thus, instead of calibrating the price-adjustment parameter to empirical work on the frequency of price adjustment, we calibrate it to Levy et al.'s (1997) estimates of the costs of price adjustment. Both the Calvo and Rotemberg approaches are reduced-forms, but the Rotemberg framework seems likely to be more appropriate as a stand-in for various costs of price change than the Calvo framework. ${ }^{1}$ Additionally, the Rotemberg model is analytically quite simple, even when we consider trends in relative prices - nowhere in the paper do we need to rely on approximations in solving the model. That said, the qualitative results presented here are likely to hold up in the Calvo model or other staggered price-setting models.

The paper proceeds as follows. In Section 2 we describe the model in full detail, while in Section 3 we derive the conditions that characterize an equilibrium in which relative prices are diverging at a constant rate because of trend differences in productivity growth. In Section 4 we show how the optimal steady-state inflation rate varies with relative productivity growth and relative price-adjustment costs. In Section 5 we study optimal inflation on a period-by-period basis in a version of the model calibrated so that the two sectors represent energy and all other goods and services. For this exercise we use an ad-hoc static

\footnotetext{
${ }^{1}$ One example of a cost of price change for which the quadratic costs could be standing in is confusion created on the part of shoppers when nominal prices change. In the Calvo model, the costs of inflation are associated not with changes in prices but with variation in prices across goods at a point in time.
} 
criterion that takes into account only current price-adjustment costs in each period. Section 6 concludes.

\section{MODEL}

In this section we will describe a complete macroeconomic model in which there are a large number of households, a large number of firms, and a monetary authority. The households are all identical; they consume the many goods produced by firms, which we will group into two categories called sector 1 and sector 2 , and they supply labor that the firms use to produce those goods. Firms are monopolistically competitive, each one producing a unique good. Each firm has monopoly power for the good it produces, but it faces competition from the many other goods that are close substitutes according to households' preferences. Firms produce consumption goods using labor only, and productivity may be increasing steadily over time, at different rates for the two sectors. Firms set the dollar price for their goods, and there is a cost of changing price from one period to the next. The monetary authority chooses the rate of inflation, that is the change in the price index for the household's consumption basket. Unlike much of the quantitative dynamic stochastic general equilibrium literature, for the sake of simplicity the model does not incorporate any mechanisms to generate strategic complementarities among price-setting firms.

\section{Households}

The representative household is infinitely lived, discounts future utility at rate $\beta$, and has preferences over consumption $\left(c_{t}\right)$ and labor supply $\left(h_{t}\right)$ of two composite goods $\left(c_{k, t}, k=1,2\right)$, and labor supply $\left(h_{t}\right)$ given by

$$
\sum_{t=0}^{\infty} \beta^{t}\left(\ln c_{t}-\chi h_{t}\right)
$$

where the consumption basket $c_{t}$ aggregates two sectors or categories $\left(c_{k, t}, k=1,2\right)$,

$$
c_{t}=c_{1, t}^{\nu} c_{2, t}^{1-\nu},
$$

and each category is itself a composite of a continuum of differentiated products $\left(c_{k, t}(z)\right)$ :

$$
c_{k, t}=\left(\int_{0}^{1} c_{k, t}(z)^{\frac{\varepsilon-1}{\varepsilon}} d z\right)^{\frac{\varepsilon}{\varepsilon-1}}, k=1,2 .
$$


According to (2), consumers have a preference for variety - they would prefer to smooth their consumption of category $k$ goods across all the goods in that category. There is a competitive labor market in which the real wage is $w_{t}$ per unit of time. Households own the firms and receive a total nominal dividend payment from firms of $\Pi_{t}$.

The household's budget constraint is as follows, in dollar terms:

$$
P_{t} c_{t}=P_{t} w_{t} h_{t}+\Pi_{t}
$$

or, in real terms:

$$
c_{t}=w_{t} h_{t}+\frac{\Pi_{t}}{P_{t}}
$$

where $P_{t}$ is the overall price level.

\section{Optimality Conditions}

From the utility function and the budget constraint, the household's intratemporal first-order conditions representing optimal choice of labor input and consumption are given by

$$
\lambda_{t} w_{t}=\chi
$$

and

$$
\lambda_{t}=1 / c_{t},
$$

where $\lambda_{t}$ is the Lagrange multiplier on the budget constraint (3) - it can also be thought of as the marginal utility of an additional unit of consumption at time $t$. In (4), the income from an additional unit of time devoted to work is equated to the utility cost of that time. And in (5) the marginal utility of consumption is equated to the value of those resources in other uses.

Recall that overall consumption $c_{t}$ is composed of consumption from two sectors, $c_{1, t}$ and $c_{2, t}$, and sectoral consumption is an aggregate of a continuum of differentiated goods. Although the consumer's problem does not involve subperiods, it can be useful to think of the consumer as first choosing overall consumption $\left(c_{t}\right)$, then, given $c_{t}$, choosing the optimal split between $c_{1, t}$ and $c_{2, t}$, and finally, given those sectoral consumptions, choosing the optimal allocation across differentiated products within each sector $\left(c_{k, t}(z)\right)$.

The optimality condition for the level of overall consumption is (5). The optimal choice of consumption from each sector minimizes the cost of consuming $c_{t}$ given the sectoral price indices $P_{1, t}$ and $P_{2, t}$ :

$$
\begin{gathered}
\operatorname{Min}_{c_{1, t}, c_{2, t}}\left\{P_{1, t} c_{1, t}+P_{2, t} c_{2, t}\right\} \\
\text { s.t. } c_{t}=c_{1, t}^{\nu} c_{2, t}^{1-\nu} .
\end{gathered}
$$


The multiplier on the constraint in (6) is the nominal marginal cost of an additional unit of consumption - the price level. Therefore we denote the multiplier as $P_{t}$, and the first-order conditions are as follows:

$$
\begin{aligned}
& \frac{c_{1, t}}{c_{2, t}}=\nu^{1 /(1-\nu)}\left(\frac{P_{1, t}}{P_{t}}\right)^{1 /(\nu-1)} \\
& \frac{c_{1, t}}{c_{2, t}}=(1-\nu)^{-1 / \nu}\left(\frac{P_{2, t}}{P_{t}}\right)^{1 / \nu} .
\end{aligned}
$$

Analogously, the optimal allocation of consumption within each sector minimizes the cost of consuming $c_{1, t}$ and $c_{2, t}$ given the prices of the differentiated products, and the multiplier on the constraint is the sectoral price index - the nominal marginal cost of purchasing one unit of the sectoral composite good:

$$
\begin{gathered}
\operatorname{Min}_{c_{k, t}(z)}\left(\int_{0}^{1} P_{k, t}(z) c_{k, t}(z) d z\right) \\
\text { s.t. } c_{k, t}=\left(\int_{0}^{1} c_{k, t}(z)^{\frac{\varepsilon-1}{\varepsilon}} d z\right)^{\frac{\varepsilon}{\varepsilon-1}}, k=1,2 .
\end{gathered}
$$

The first order conditions are as follows:

$$
\frac{c_{k, t}(z)}{c_{k, t}}=\left(\frac{P_{k, t}(z)}{P_{k, t}}\right)^{-\varepsilon}, k=1,2 ; \quad z \in(0,1) .
$$

\section{The Overall Price Level and Category}

\section{Price Levels}

Above, we derived the optimality conditions describing how households allocate consumption across sectors and across goods within each sector. Here we use those optimality conditions to show how prices within each sector aggregate to sectoral price indices and how the sectoral price indices aggregate to the overall price level.

From (11) and (12) we have

$$
c_{k, t}=\left(\int_{0}^{1}\left(\frac{P_{k, t}(z)}{P_{k, t}}\right)^{1-\varepsilon} c_{k, t}^{\frac{\varepsilon-1}{\varepsilon}} d z\right)^{\frac{\varepsilon}{\varepsilon-1}}, k=1,2,
$$

which can be manipulated to yield an expression for each sectoral price index as a function of individual goods prices within the sector:

$$
P_{k, t}=\left(\int_{0}^{1}\left(P_{k, t}(z)\right)^{1-\varepsilon} d z\right)^{\frac{1}{1-\varepsilon}}, k=1,2 .
$$

This expression for the category price indices plays an important role in staggered price-setting models, where there is equilibrium dispersion 
in the prices of like goods (varieties). Here however, all prices within a category will be identical in the equilibria we consider. ${ }^{2}$

Across sectors, if productivity is not identical then there will be price differentials. From (8) and (9) we have

$$
(1-\nu)^{-1 / \nu}\left(\frac{P_{2, t}}{P_{t}}\right)^{1 / \nu}=\nu^{1 /(1-\nu)}\left(\frac{P_{1, t}}{P_{t}}\right)^{1 /(\nu-1)}
$$

which can be manipulated to yield an expression for the price level as a function of the sectoral price indices:

$$
P_{t}=\left(\frac{P_{1, t}}{\nu}\right)^{\nu}\left(\frac{P_{2, t}}{1-\nu}\right)^{1-\nu} .
$$

\section{Firms}

Each firm $z$ in sector $k$ produces consumption goods with a technology that is linear in labor:

$$
y_{k, t}(z)=a_{k, t} h_{k, t}(z) .
$$

In equilibrium the firm's output will be identical to households' consumption of that good $\left(y_{k, t}(z)=c_{k, t}(z)\right)$, but for the purposes of this section we will maintain a distinction between output and consumption. Productivity $\left(a_{k, t}\right)$ may vary across time and across sectors, but it is the same across firms within a sector. Marginal cost for each firm in sector $k\left(\psi_{k, t}\right)$ is given by the ratio of the wage to the marginal product of labor:

$$
\psi_{k, t}=w_{t} / a_{k, t}
$$

Firms face a cost $\left(\xi_{k, t}(z)\right)$ in terms of labor of changing the nominal price of the good they produce $(z)$. The cost is proportional to output and is affected by the same productivity shifter as regular goods production:

$$
\xi_{k, t}(z)=\frac{\theta_{k}}{2}\left(\frac{y_{k, t}(z)}{a_{k, t}}\right)\left(\frac{P_{k, t}(z)}{P_{k, t-1}(z)}-1\right)^{2} .
$$

An individual firm chooses its price each period to maximize the expected present value of profits, where profits in any single period

\footnotetext{
${ }^{2}$ In principle one could imagine equilibria in which initial dispersion in prices was sustained over time, but these equilibria have not been the focus of attention in Rotemberg models.
} 
are given by revenue minus costs of production minus costs of price adjustment, plus a per-unit subsidy from the government. ${ }^{3}$

From (12), the demand curve facing firm $z$ in sector $k$ is $y_{k, t}(z)=$ $\left(P_{k, t}(z) / P_{k, t}\right)^{-\varepsilon} y_{k, t}$, so the profit maximization problem for such a firm is

$$
\begin{aligned}
& \max _{P_{k, t+j}(z)} \sum_{j=0}^{\infty} \beta^{j}\left(\frac{\lambda_{t+j}}{\lambda_{t}}\right)\left[(1+\tau) \frac{P_{k, t+j}(z)}{P_{t+j}}\left(\frac{P_{k, t+j}(z)}{P_{k, t+j}}\right)^{-\varepsilon} y_{k, t+j}\right. \\
& -\frac{w_{t+j}}{a_{k, t+j}}\left(\frac{P_{k, t+j}(z)}{P_{k, t+j}}\right)^{-\varepsilon} y_{k, t+j} \\
& \left.-\frac{\theta_{k}}{2} w_{t+j}\left(\left(\frac{P_{k, t+j}(z)}{P_{k, t+j}}\right)^{-\varepsilon} \frac{y_{k, t+j}}{a_{k, t+j}}\right)\left(\frac{P_{k, t+j}(z)}{P_{k, t+j-1}(z)}-1\right)^{2}\right] .
\end{aligned}
$$

The first term in the square brackets is the real revenue a firm earns charging price $P_{t+j}(z)$ in period $t+j$; it sells $\left(P_{k, t+j}(z) / P_{k, t+j}\right)^{-\varepsilon} y_{k, t+j}$ units of goods for relative price $P_{t+j}(z) / P_{t+j}$, and it receives a subsidy of $\tau$ per unit sold. The second term represents the cost of producing those goods, and the third term represents the price-adjustment cost.

Note that the price chosen in any period shows up only in two periods of the infinite sum. Thus, the part of the objective function relevant for the choice of a price in period $t$ is

$$
\begin{aligned}
& (1+\tau) \frac{P_{k, t}(z)}{P_{t}}\left(\frac{P_{k, t}(z)}{P_{k, t}}\right)^{-\varepsilon} y_{k, t}-\frac{w_{t}}{a_{k, t}}\left(\frac{P_{k, t}(z)}{P_{k, t}}\right)^{-\varepsilon} y_{k, t} \\
& -\frac{\theta_{k}}{2} w_{t}\left(\frac{\left(P_{k, t}(z) / P_{k, t}\right)^{-\varepsilon} y_{k, t}}{a_{k, t}}\right)\left(\frac{P_{k, t}(z)}{P_{k, t-1}(z)}-1\right)^{2} \\
& -\frac{\lambda_{t+1}}{\lambda_{t}} \frac{\beta \theta_{k}}{2} w_{t+1}\left(\frac{\left(P_{k, t+1}(z) / P_{k, t+1}\right)^{-\varepsilon} y_{k, t+1}}{a_{k, t+1}}\right)\left(\frac{P_{k, t+1}(z)}{P_{k, t}(z)}-1\right)^{2} .
\end{aligned}
$$

\footnotetext{
${ }^{3}$ The purpose of including the subsidy is to allow us to focus attention mainly on the direct costs of price adjustment, rather than secondary effects through changes in markups.
} 
The first-order condition is:

$$
\begin{aligned}
0= & \frac{(1+\tau)(1-\varepsilon)}{P_{t}}\left(\frac{P_{k, t}(z)}{P_{k, t}}\right)^{-\varepsilon} y_{k, t}+\frac{\varepsilon w_{t}}{a_{k, t} P_{k, t}}\left(\frac{P_{k, t}(z)}{P_{k, t}}\right)^{-\varepsilon-1} y_{k, t} \\
& -\theta_{k} w_{t}\left(\frac{\left(P_{k, t}(z) / P_{k, t}\right)^{-\varepsilon} y_{k, t}}{a_{k, t}}\right)\left(\frac{P_{k, t}(z)}{P_{k, t-1}(z)}-1\right) \frac{1}{P_{k, t-1}(z)} \\
& +\frac{\varepsilon \theta_{k}}{2} w_{t}\left(\frac{1}{a_{k, t}}\right) \frac{1}{P_{k, t}}\left(\frac{P_{k, t}(z)}{P_{k, t}}\right)^{-\varepsilon-1} y_{k, t}\left(\frac{P_{k, t}(z)}{P_{k, t-1}(z)}-1\right)^{2} \\
& +\frac{\lambda_{t+1}}{\lambda_{t}} \beta \theta_{k} w_{t+1} \frac{y_{k, t+1}}{a_{k, t+1}}\left(\frac{P_{k, t+j}(z)}{P_{k, t+j}}\right)^{-\varepsilon}\left(\frac{P_{k, t+1}(z)}{P_{k, t}(z)}-1\right) \frac{P_{k, t+1}(z)}{\left(P_{k, t}(z)\right)^{2}} .
\end{aligned}
$$

Absent price-adjustment costs (if $\theta_{k}$ were zero) the firm would choose price in order to balance the marginal revenue and marginal cost of further price adjustment, yielding a constant markup over marginal cost: $P_{k, t}(z)=(\varepsilon /((\varepsilon-1)(1+\tau)))\left(w_{t} / a_{k, t}\right) P_{t}$. With price-adjustment costs, the same principle applies, but marginal cost is now more complicated, because price adjustment also affects (marginal) price-adjustment costs in the current and subsequent periods. There is no closed form solution for the optimal price, although we will see below that in a symmetric equilibrium the expression simplifies dramatically.

\section{Monetary Authority}

In reality, the monetary authority controls instrument variables, like the size of its balance sheet or some administered interest rates. Inflation is then an equilibrium outcome. In the model we assume that the monetary authority directly controls the inflation rate: $\pi_{t}=P_{t} / P_{t-1}$. How central banks determine the inflation rate, and how precisely they can control the inflation rate, are interesting and important questions, but they are beyond the scope of this paper.

\section{Equilibrium Conditions}

We consider a symmetric equilibrium where all firms in the same sector charge the same price and hence produce the same quantity. Thus we have

$$
\left.\begin{array}{rl}
P_{k, t}(z) & =P_{k, t} \\
y_{k, t}(z) & =y_{k, t}
\end{array}\right\}, \quad k=1,2 .
$$

And because goods are produced for consumption only, in a symmetric equilibrium with all firms in sector $k$ producing the same quantity, the goods market-clearing condition for each sector is

$$
y_{k, t}=c_{k, t} \text {. }
$$


The labor market-clearing condition states that labor supplied by households $\left(h_{t}\right)$ must be equal to the sum of labor used in production and labor used in price adjustment. Because of symmetry, we can just refer to the sectoral aggregates instead of individual firm inputs:

$$
h_{t}=h_{1, t}+h_{2, t}+\xi_{1, t}+\xi_{2, t} .
$$

Using the price-adjustment cost function (15) and the technology for goods production, and imposing (16), we have

$$
h_{t}=\frac{y_{1, t}}{a_{1, t}} \cdot\left(1+\frac{\theta_{1}}{2}\left(\pi_{1, t}-1\right)^{2}\right)+\frac{y_{2, t}}{a_{2, t}} \cdot\left(1+\frac{\theta_{2}}{2}\left(\pi_{2, t}-1\right)^{2}\right),
$$

where $\pi_{k, t}$ denotes the gross rate of sectoral price change $\left(\pi_{k, t}=\right.$ $\left.P_{k, t} / P_{k, t-1}\right)$.

Imposing symmetry on the firms' first-order condition yields the following expression, which we will refer to as the sectoral Phillips curve:

$$
\begin{aligned}
0= & (1+\tau)(1-\varepsilon) p_{k, t} y_{k, t}+\varepsilon w_{t} \frac{y_{k, t}}{a_{k, t}} \\
& -\theta_{k} w_{t}\left(\frac{y_{k, t}}{a_{k, t}}\right)\left(\pi_{k, t}-1\right) \pi_{k, t} \\
& +\frac{\varepsilon \theta_{k}}{2} w_{t}\left(\frac{y_{k, t}}{a_{k, t}}\right)\left(\pi_{k, t}-1\right)^{2} \\
& +\frac{\lambda_{t+1}}{\lambda_{t}} \beta \theta_{k} w_{t+1}\left(\frac{y_{k, t+1}}{a_{k, t+1}}\right)\left(\pi_{k, t+1}-1\right)\left(\pi_{k, t+1}\right),
\end{aligned}
$$

where we use $p_{k, t}$ to denote the relative price of the sector $k$ good: $p_{k, t} \equiv P_{k, t} / P_{t}$. The other equilibrium conditions are the household's first-order conditions (4), (5), (8), and (9) and the price level equation (14), which can also be written as a restriction on relative prices:

$$
1=\left(\frac{p_{1, t}}{\nu}\right)^{\nu}\left(\frac{p_{2, t}}{1-\nu}\right)^{1-\nu} ;
$$

an increase in the relative price of one good implies a decrease in the relative price of the other good.

\section{A STEADY STATE WITH TRENDING RELATIVE PRICES}

Thus far, we have not specified the processes for sectoral productivity $a_{k, t}$, which, along with the inflation rate, are the model's driving variables - that is, the exogenous variables that determine the nature of equilibrium outcomes. In this section we impose constant growth rates for productivity and derive the equilibrium values of the model's 
endogenous variables as functions of parameters and the rates of productivity growth and inflation. Then we compute some examples for particular parameter values. We will only consider an equilibrium in which all growth rates are constant and where labor input is constant in both sectors. ${ }^{4}$

\section{The System of Equations}

Assume that productivity grows at constant gross rate $\mu_{k}$ in sector $k$, and make the normalizing assumption that in period zero the level of productivity in both sectors was 1 . Then we have

$$
a_{k, t}=\mu_{k}^{t} .
$$

If we also assume that the inflation rate is constant, equal to $\pi$, then we can write the steady-state Phillips curve equations as follows (at this point we are leaving $t$ subscripts on all variables, because it is not yet obvious which variables will be constant in a steady state with growth and how to normalize all variables in that steady state):

$$
\begin{aligned}
0= & (1+\tau)(1-\varepsilon) p_{k, t} y_{k, t}+\varepsilon \frac{w_{t}}{\mu_{k}^{t}} y_{k, t} \\
& -\theta_{k} w_{t}\left(\frac{y_{k, t}}{\mu_{k}^{t}}\right)\left(\frac{p_{k, t}}{p_{k, t-1}} \pi-1\right) \frac{p_{k, t}}{p_{k, t-1}} \pi \\
& +\frac{\varepsilon \theta_{k}}{2} w_{t}\left(\frac{1}{\mu_{k}^{t}}\right) y_{k, t}\left(\frac{p_{k, t}}{p_{k, t-1}} \pi-1\right)^{2} \\
& +\frac{\lambda_{t+1}}{\lambda_{t}} \beta \theta_{k} w_{t+1}\left(\frac{y_{k, t+1}}{\mu_{k}^{t+1}}\right)\left(\frac{p_{k, t+1}}{p_{k, t}} \pi-1\right)\left(\frac{p_{k, t+1}}{p_{k, t}} \pi\right), k=1,2 .
\end{aligned}
$$

From the household's first-order conditions, (4), (5), (8), and (9), the definition of the consumption index (7), and the goods market clearing condition (17), we can express output in the two sectors as a function of the wage and relative prices:

$$
\begin{aligned}
y_{1, t} & =\frac{\nu}{\chi} \frac{w_{t}}{p_{1, t}} \\
y_{2, t} & =\frac{1-\nu}{\chi} \frac{w_{t}}{p_{2, t}}
\end{aligned}
$$

\footnotetext{
${ }^{4}$ We have not proved that the equilbrium we study is unique, though we suspect that it is.
} 
Finally, we use these last two equations to eliminate sectoral outputs in the Phillps curve. After simplifying, we have

$$
\begin{aligned}
0= & (1+\tau)(1-\varepsilon)+\varepsilon \frac{w_{t}}{\mu_{1}^{t} p_{1, t}} \\
& -\theta_{1}\left(\frac{w_{t}}{\mu_{1}^{t}}\right)\left(\frac{p_{1, t}}{p_{1, t-1}} \pi-1\right) \frac{\pi}{p_{1, t-1}} \\
& +\frac{\varepsilon \theta_{1}}{2} \frac{w_{t}}{\mu_{1}^{t} p_{1, t}}\left(\frac{p_{1, t}}{p_{1, t-1}} \pi-1\right)^{2} \\
& +\beta \theta_{1}\left(\frac{w_{t+1}}{\mu_{1}^{t+1} p_{1, t+1}}\right)\left(\frac{p_{1, t+1}}{p_{1, t}} \pi-1\right)\left(\frac{p_{1, t+1}}{p_{1, t}} \pi\right) .
\end{aligned}
$$

Analogously, for sector 2 the Phillips curve is as follows:

$$
\begin{aligned}
0= & (1+\tau)(1-\varepsilon)+\varepsilon \frac{w_{t}}{\mu_{2}^{t} p_{2, t}} \\
& -\theta_{2}\left(\frac{w_{t}}{\mu_{2}^{t}}\right)\left(\frac{p_{2, t}}{p_{2, t-1}} \pi-1\right) \frac{\pi}{p_{2, t-1}} \\
& +\frac{\varepsilon \theta_{2}}{2} \frac{w_{t}}{\mu_{2}^{t} p_{2, t}}\left(\frac{p_{2, t}}{p_{2, t-1}} \pi-1\right)^{2} \\
& +\beta \theta_{2}\left(\frac{w_{t+1}}{\mu_{2}^{t+1} p_{2, t+1}}\right)\left(\frac{p_{2, t+1}}{p_{2, t}} \pi-1\right)\left(\frac{p_{2, t+1}}{p_{2, t}} \pi\right) .
\end{aligned}
$$

Together with the restriction on relative prices implied by the price index (19), these two Phillips curve equations represent a system of three equations in the three endogenous variables $w_{t}, p_{1, t}$, and $p_{2, t}$. In order to make further progress however, we need to use the constant productivity growth assumption to find the growth rates of wages and relative prices.

\section{Productivity Growth Determines Growth Rates of Wages and Relative Prices}

From the household's optimality conditions, (4) and (5), we know that $w_{t}=\chi c_{t}$, so the real wage must grow at the same rate as consumption. What do we know about the growth rate of $c$ ? Let $\gamma_{c_{k}}$ be the gross growth rate of $c_{k}$. Then, if we denote the growth rate of consumption as $\gamma_{c}$, we have $\gamma_{c}=\gamma_{c_{1}}^{\nu} \gamma_{c_{2}}^{1-\nu}$ :

$$
\underbrace{c_{t}}_{\gamma_{c}}=(\underbrace{c_{1, t}}_{\gamma_{c_{1}}})^{\nu}(\underbrace{c_{2, t}}_{\gamma_{c_{2}}})^{1-\nu},
$$


Now consider the growth rates of $c_{1}$ and $c_{2}$. With labor input constant in the two sectors, output grows at the rate of productivity, so we know the growth rates of $c_{1}, c_{2}, c$, and $w$ :

$$
\begin{aligned}
\gamma_{c_{1}} & =\mu_{1} \\
\gamma_{c_{2}} & =\mu_{2} \\
\gamma_{c} & =\mu_{1}^{\nu} \mu_{2}^{1-\nu} \\
\gamma_{w} & =\mu_{1}^{\nu} \mu_{2}^{1-\nu}
\end{aligned}
$$

To determine the growth rates of relative prices we use this same reasoning on (21) and (22):

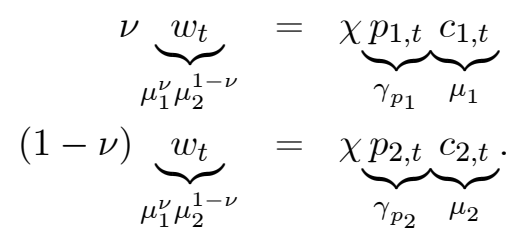

That is

$$
\begin{aligned}
\gamma_{p_{1}} & =\left(\mu_{1} / \mu_{2}\right)^{\nu-1} \\
\gamma_{p_{2}} & =\left(\mu_{1} / \mu_{2}\right)^{\nu} .
\end{aligned}
$$

Note that the growth rates of relative prices must cancel out when aggregated according to the price index (19), and the growth rates we just derived indeed have this property.

\section{The Time Paths of Wages and Relative Prices}

We have now determined the growth rates of wages and relative prices, but we need to use the price index and Phillips curve equations to determine the levels of those variables. To that end, we plug into the Phillips curves and the price index expressions for wages and relative prices that use the trends we just derived together with unknown initial levels:

$$
\begin{aligned}
w_{t} & =w_{0} \cdot\left(\mu_{1}^{\nu} \mu_{2}^{1-\nu}\right)^{t} \\
p_{1, t} & =p_{1,0} \cdot\left(\mu_{1} / \mu_{2}\right)^{(\nu-1) t} \\
p_{2, t} & =p_{2,0} \cdot\left(\mu_{1} / \mu_{2}\right)^{\nu t} .
\end{aligned}
$$

The equations will then be used to determine the initial levels $w_{0}, p_{1,0}$, and $p_{2,0}$. Once we have simplified the Phillips curves and collected 
terms, we have

$$
\begin{gathered}
\frac{p_{1,0}}{w_{0}}=\frac{\varepsilon}{(\varepsilon-1)(1+\tau)} \times \\
\left\{1-\theta_{1}\left(\left(\frac{\mu_{1}}{\mu_{2}}\right)^{\nu-1} \pi-1\right) \times\right. \\
\left.\left[\left(\frac{1-\beta}{\varepsilon}\right)\left(\frac{\mu_{1}}{\mu_{2}}\right)^{\nu-1} \pi-\frac{1}{2}\left(\left(\frac{\mu_{1}}{\mu_{2}}\right)^{\nu-1} \pi-1\right)\right]\right\}
\end{gathered}
$$

and analogously for good 2 ,

$$
\begin{gathered}
\frac{p_{2,0}}{w_{0}}=\frac{\varepsilon}{(\varepsilon-1)(1+\tau)} \times \\
\left\{1-\theta_{2}\left(\left(\frac{\mu_{1}}{\mu_{2}}\right)^{-\nu} \pi-1\right) \times\right. \\
\left.\left[\left(\frac{1-\beta}{\varepsilon}\right)\left(\frac{\mu_{1}}{\mu_{2}}\right)^{-\nu} \pi-\frac{1}{2}\left(\left(\frac{\mu_{1}}{\mu_{2}}\right)^{-\nu} \pi-1\right)\right]\right\} .
\end{gathered}
$$

And the price index equation is

$$
1=\left(\frac{p_{1,0}}{\nu}\right)^{\nu}\left(\frac{p_{2,0}}{1-\nu}\right)^{1-\nu} .
$$

So we have three equations in $p_{1,0}, p_{2,0}$, and $w_{0}$. For any values of the parameters $\left(\varepsilon, \nu, \beta, \mu_{j}, \theta_{j},\right)$ and the inflation rate $(\pi)$ it is straightforward to calculate the values of all the endogenous variables. First, $p_{1,0}, p_{2,0}$, and $w$ come from solving the last three equations. The other important variables, $c$ and $h$, can easily be calculated from (21), (22), and (18). Detailed derivations are contained in the Appendix.

\section{OPTIMAL STEADY-STATE INFLATION}

In this section we explore the model's implications for the optimal steady-state inflation rate, focusing on how differential productivity growth rates and differential price-adjustment costs in the two sectors affect the optimal inflation rate. Without that sectoral heterogeneity, the question would be relatively simple, although there is one subtlety that we will quickly dispense with. In a one-sector version of the model, or equivalently a model without heterogeneity in productivity growth, it would be possible to eliminate all direct, steady-state costs of price adjustment by maintaining a zero inflation rate: Prices would never need to change. However, in the absence of an appropriate subsidy $\tau$, zero inflation would not be the welfare-maximizing steady-state inflation rate because a small amount of inflation would reduce the average 
markup of price over marginal cost toward its efficient level of zero. For our purposes, the latter effect is a nuisance-it detracts attention from the focus of the paper. So in what follows we will set the subsidy $\tau$ so that it exactly offsets the markup in a steady state with zero inflation and identical sectors: $\tau=1 /(\varepsilon-1)$.

The model is simple enough that we can use the equations above to derive the level of steady-state welfare as an explicit function of inflation. However, the expressions become somewhat complicated, so we simply reiterate here that inflation enters the welfare calculation through two channels. First, there is the direct effect on priceadjustment costs (see [18]). Second, there is an effect on relative prices and the real wage, that can be seen in (25)-(29). This is the markup effect mentioned in the previous paragraph. For any values of the parameters and for a range of inflation rates, it would be possible to choose the subsidy to eliminate the markup in one sector, and the markup could be eliminated in both sectors with sector-specific subsidies. For simplicity we fix the subsidy at the level that eliminates the markup in a zero-inflation steady state with common productivity growth across sectors. Later on we will abstract entirely from the markup effects of inflation. However, here our calculations of optimal steady-state welfare will incorporate both the price-adjustment cost and markup effects.

To help interpret the figures below, recall that the overall price level is related to the sectoral price indices as follows,

$$
P_{t}=\left(\frac{P_{1, t}}{\nu}\right)^{\nu}\left(\frac{P_{2, t}}{1-\nu}\right)^{1-\nu} .
$$

The inflation rate, then, can be written as a function of the rates of price change in the two sectors:

$$
\pi_{t}=\frac{P_{t}}{P_{t-1}}=\pi_{1, t}^{\nu} \pi_{2, t}^{1-\nu}
$$

Using the log approximation, for moderate rates of price change the net inflation rate is approximately equal to the share weighted average of the two sectoral rates of price change:

$$
\pi_{t} \approx \nu \pi_{1, t}+(1-\nu) \pi_{1, t}
$$

\section{Parameter Values}

To study the effect of relative productivity growth and relative priceadjustment costs on the optimal inflation rate, we set the parameters $\beta$ and $\varepsilon$ at standard values in the literature, 0.99 and 10, respectively. Interpreting a model time period as one quarter, $\beta=0.99$ implies an annual real interest rate of about 4 percent. With $\varepsilon=10$, the average 
Figure 1 Optimal Inflation with $v=\mathbf{0 . 5}$

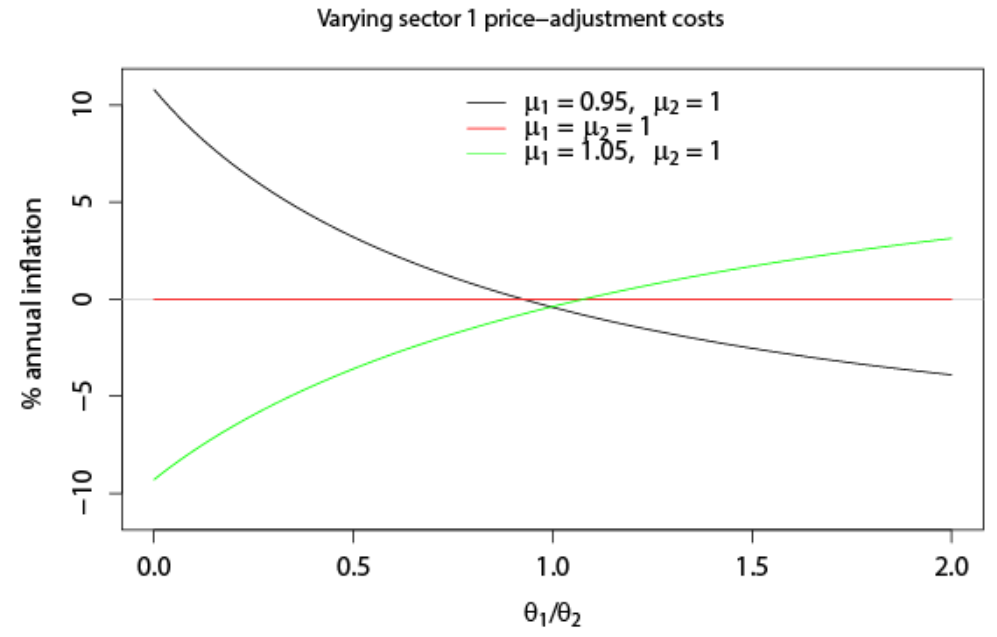

markup is around 11 percent absent the subsidy. As a benchmark we set the rates of productivity growth in each sector to 1 and the priceadjustment cost parameter $\left(\theta_{j}\right)$ in each sector to 140 . With $\theta_{1}=\theta_{2}=$ 140 , the steady-state price-adjustment costs associated with a 1 percent quarterly price change amount to 0.7 percent of a firm's revenue. This is the average number estimated by Levy et al. (1997) in their study of supermarkets.

\section{Relative Price Trends and The Optimal Inflation Rate}

Figures 1 and 2 plot the optimal steady-state inflation rate as a function of relative price-adjustment costs (Figure 1) and relative productivity growth (Figure 2) for the case where consumers' expenditure shares are equal for the two sectors; that is, $\nu=0.5$. In Figure 1, the black line represents a case with relatively low productivity growth in sector 1 $\left(\mu_{1} / \mu_{2}=0.95\right)$, the red line is constant and equal productivity in both sectors $\left(\mu_{1}=\mu_{2}=1\right)$, and the green line is relatively high productivity growth in sector $1\left(\mu_{1} / \mu_{2}=1.05\right)$. Since it is simplest, focus first on the red line. When productivity is constant in both sectors, relative prices are also constant, and when relative prices are constant there is no need for any nominal prices to change. Thus, since zero inflation 
Figure 2 Optimal Inflation with $v=\mathbf{0 . 5}$

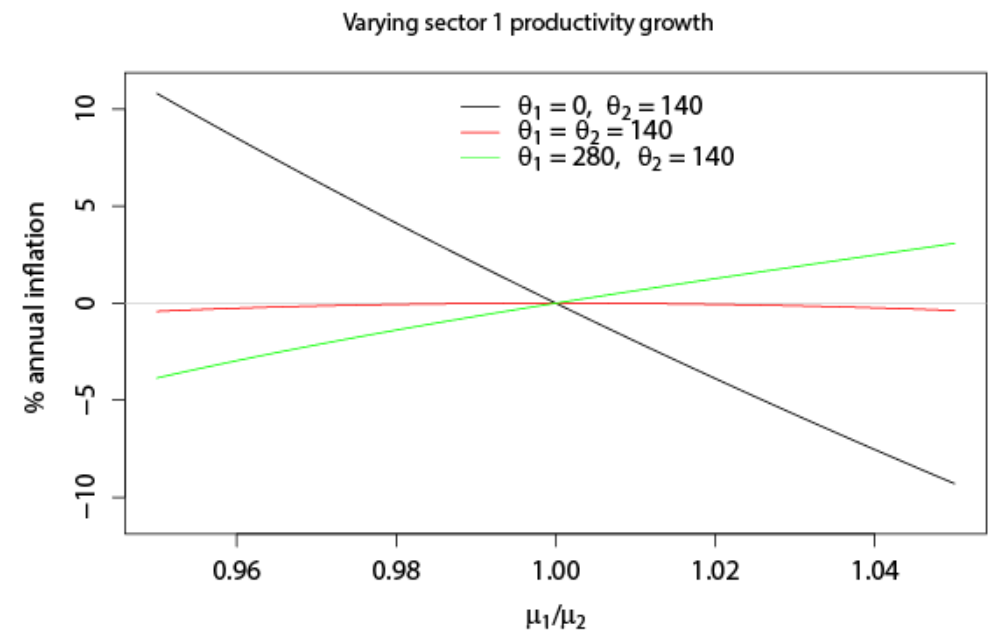

eliminates the costs of price change, the optimal inflation rate is zero because there are price-adjustment costs in sector 2; this holds regardless of the level of price-adjustment costs in sector 1 . When productivity growth does vary across sectors, relative prices must change in steady state - specifically, the sector with low productivity growth should see its relative price rise. In order for relative prices to change, at least one nominal price needs to change. In the case when productivity growth is lower in sector 1 (black line), the optimal inflation rate is decreasing in sector 1's price-adjustment costs: When sector 1's adjustment costs are low ( $\theta_{1} / \theta_{2}$ is low), it is optimal for the required increase in sector 1 relative prices to occur through an increase in sector 1 nominal prices because those price increases are not costly. In contrast, when $\theta_{1} / \theta_{2}$ is high, the increase in sector 1 relative prices optimally occurs mainly through a decrease in sector 2 nominal prices, because those price decreases are low cost. The explanation for the case of high sector 1 productivity growth (green line) essentially involves reversing the signs relative to the black line.

Figure 2 displays similar relationships, except that relative productivity growth varies continuously on the horizontal axis, and the three lines represent different levels of relative price-adjustment costs. The black and green lines represent low and high levels of sector 1 price-adjustment costs $\left(\theta_{1}\right)$, and the red line is the case where $\theta_{1}=\theta_{2}$. 
Figure 3 Optimal Inflation with $v=0.05$

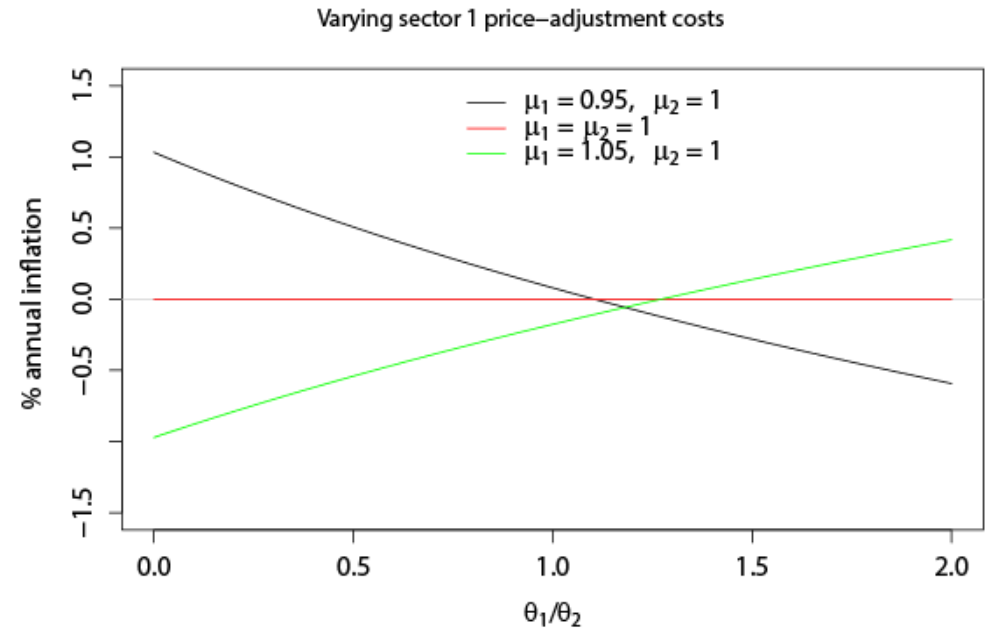

A curious feature of Figures 1 and 2 is that when price-adjustment costs are equal in the two sectors, a small amount of deflation is optimal. In Figure 1, the point where the black and green lines intersect exhibits deflation, and in Figure 2 the red line exhibits deflation everywhere except when productivity growth is equal in the two sectors. To understand this result, consider the case where there is positive productivity growth in sector 1 and zero productivity growth in sector 2 (i.e., $\mu_{1}>1, \mu_{2}=1$ ). Given the quadratic price-adjustment costs, zero overall inflation might seem optimal: Prices would be falling somewhat in sector 1 and rising somewhat in sector 2 . The problem with zero inflation is that price-adjustment costs would actually be larger in sector 2 (with rising prices) than in sector 1 . Price-adjustment costs can be reduced by shifting some of the price-adjustment burden toward sector 1 , and this requires slight deflation. Formally, with $\nu=0.5$, from (31) zero inflation implies $\pi_{1}=1 / \pi_{2}$. Price-adjustment costs are then proportional to $\left(\pi_{1}-1\right)^{2}$ in sector 1 and proportional to $\left(1 / \pi_{1}-1\right)^{2}$ in sector 2 . With $\pi_{1}<1$, adjustment costs would be higher in sector 2 .

Figures 3 and 4 are analogues to Figures 1 and 2 for the case where the expenditure share on sector 1 is small, just 5 percent. Note that the inflation magnitudes in these figures are much smaller. With one sector very small, nominal price changes in that sector pass through 
Figure 4 Optimal Inflation with $v=0.05$

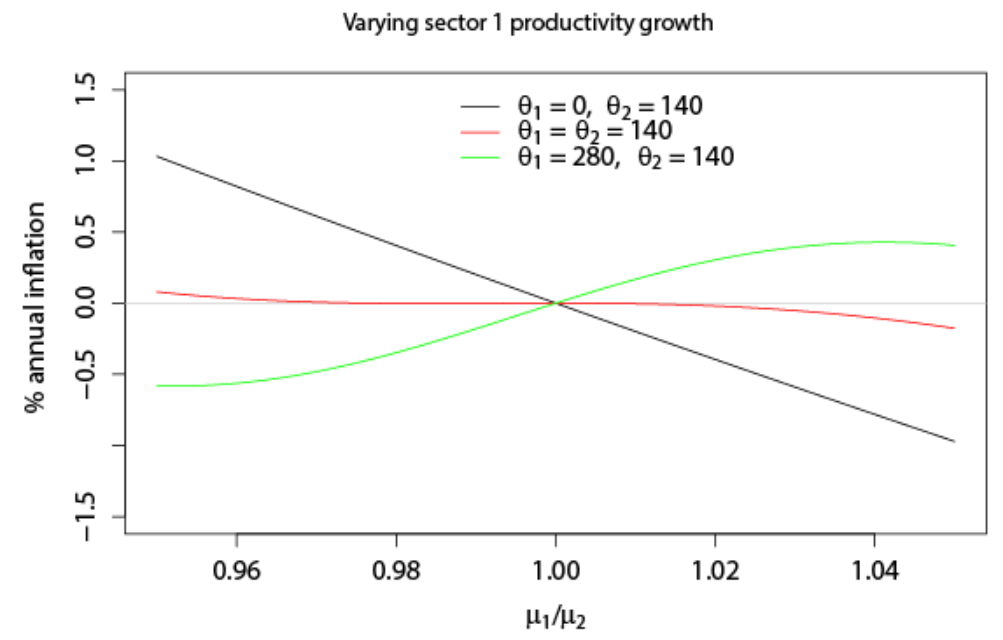

less to overall inflation (see [32]), so it is possible to achieve the desired relative price changes with less overall inflation (or deflation).

The figures above show how optimal inflation in a two-sector model varies across a wide range for relative productivity growth, relative price-adjustment costs, and relative size of the two sectors. Although the model is highly stylized, one could interpret the figures as indicating that the optimal inflation rate in the United States is actually negative. This follows from the fact that goods prices seem to be more flexible than services prices (Bils and Klenow 2004) and the price of goods relative to services has trended down over time. Optimality of deflation is not an uncommon result, but that result is typically associated with the shoe-leather costs of inflation (Friedman 1969).

\section{SHORT-RUN RELATIVE PRICE CHANGES AND OPTIMAL INFLATION}

The preceding analysis of optimal steady-state inflation is relevant for thinking about situations where there are long-run trends in relative prices across sectors. However, there are even larger short-run fluctuations in relative prices, and these can occur for goods or sectors that do not experience trend relative price changes. The obvious example is energy prices, which have fluctuated dramatically in the United States 
recently. In the presence of these large relative price movements, what is the optimal behavior of inflation period-by-period? The model laid out above can provide an answer to that question for any parameter values and any fluctuations in sectoral productivity growth - which are the natural drivers of relative prices in the model. In this section we will study an interesting special case: Sector 1 will be interpreted as energy goods and services, and sector 2 as all other personal consumption expenditure goods and services. We will assume that price-adjustment costs are zero for energy goods and services, whereas for all other goods those costs are determined by (15) with $\theta_{2}=140$, as above. ${ }^{5}$ We will further assume that there are sector-specific and, in the case of sector 2 , time-varying subsidies that make price always equal to marginal cost. Thus, the inflation rate affects only the magnitude of price-adjustment costs, given the exogenous fluctuations in relative prices. ${ }^{6}$

In the special case just described, optimal policy is trivial. The relative price of goods across the two sectors must change over time because of changes in relative productivity. With zero price-adjustment costs in sector 1, it is optimal for the entire burden of adjustment to be born by sector 1 , and this can be accomplished in every period without any distortions. That is, the markup will be zero, and zero adjustment costs will be incurred. Such a policy is related to stabilizing core inflation, except that here core inflation refers to ex-energy inflation instead of ex-food and energy. In Section 5 we derive the counterfactual inflation rate for the United States since 1959 that would have minimized price-adjustment costs under these assumptions. We then incorporate the fact that since 2012 the Federal Reserve has had a 2 percent target for inflation. We calculate modified counterfactual inflation rates that balance a desire to meet the inflation target with a desire to minimize price-adjustment costs.

\section{Time Path of Inflation Chosen to Minimize Price-Adjustment Costs}

With zero price-adjustment costs in sector 1 , the inflation rate that minimizes price-adjustment costs (call it $\pi_{t}^{a}$ ) is the inflation rate that accommodates all relative price changes with nominal price changes only for the sector 1 good. That is,

$$
\frac{\pi_{1, t}^{a}}{\pi_{2, t}^{a}}=\pi_{1, t}^{a}=\frac{p_{1, t} / p_{1, t-1}}{p_{2, t} / p_{2, t-1}}
$$

\footnotetext{
${ }^{5}$ This approach follows Aoki (2001), who used a model with Calvo price setting.

${ }^{6}$ Under the stated assumptions, the ratio of relative prices in the two sectors is given by the inverse of the ratio of productivities: $p_{2, t} / p_{1, t}=a_{1, t} / a_{2, t}$.
} 
Figure 5 Inflation Rate to Minimize Price-Adjustment Costs

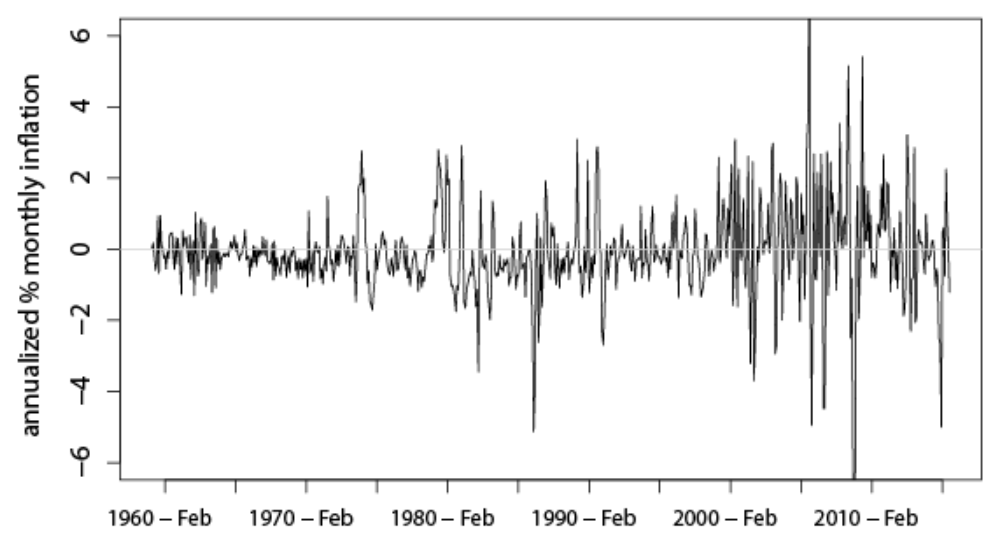

and,

$$
\pi_{t}^{a}=\left(\pi_{1, t}^{a}\right)^{\nu}
$$

which together imply

$$
\pi_{t}^{a}=\left(\frac{p_{1, t} / p_{1, t-1}}{p_{2, t} / p_{2, t-1}}\right)^{\nu}
$$

With relative price changes viewed as exogenous, and thus equal to their observed values, we can use (33) to construct a time series for $\pi_{t}^{a}$. In constructing $\pi_{t}^{a}$ we deviate from the assumptions above by allowing $\nu$ to vary each period, setting it equal to that period's observed energy expenditure share.

Figure 5 displays the monthly time series for $\pi_{t}^{a}$, the inflation rate that would have minimized price-adjustment costs under the stated assumptions. Relative prices for the energy sector are extremely volatile, and that volatility is optimally allocated entirely to nominal energy prices. Nominal energy price volatility then passes directly through to inflation. However, because the energy expenditure share is relatively low, the resulting fluctuations in inflation are much smaller than the fluctuations in energy prices. Note that since 2000 the volatility of $\pi_{t}^{a}$ has increased markedly due to an increase in the volatility of the relative price of energy. 
Figure 6 Inflation Rate to Minimize Price-Adjustment Costs, 12-month

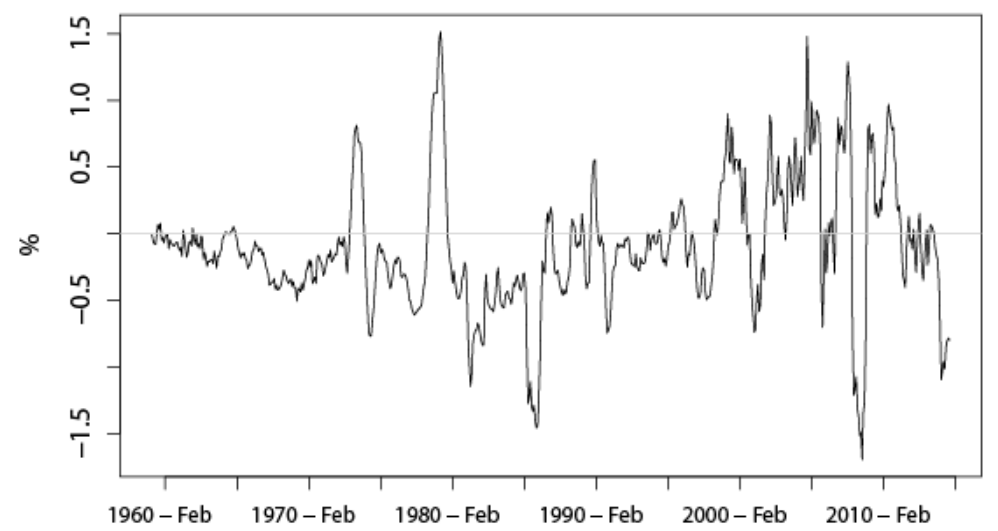

Figure 6 also plots $\pi_{t}^{a}$, but it displays that inflation rate over the preceding 12 months, instead of the monthly values. According to our simple model, for the most recently available data, adjustment costs would have been minimized with deflation of around 1.25 percent.

While Figures 5 and 6 emphasize the time series behavior of $\pi_{t}^{a}$, it is also interesting to look at the entire distribution of "optimal" inflation outcomes. Expressed as deviations from their mean, this distribution may be relevant in thinking about an appropriate band within which to target inflation. Figure 7 displays the sample distribution function of 12-month $\pi_{t}^{a}$, in deviations from its mean.

Approximately 90 percent of the time, the inflation rate that minimizes price adjustment costs lies between -1 percent and +1 percent, relative to its mean. This finding lends some tentative support to the notion that a reasonable inflation targeting band would be $+/-1$ percentage point: If the costs of inflation are given by quadratic costs of price adjustment as calibrated here, then historical fluctuations in relative energy prices imply that it is optimal to keep inflation within a +/- 1 percentage point band 90 percent of the time. From 1959 to the present, inflation has been substantially more volatile than this hypothetical distribution, with 90 percent of the observations lying between -2.2 percent and 5.5 percent relative to the mean. Of course, there 
Figure 7 Sample Distribution of Optimal Inflation Deviations From Mean

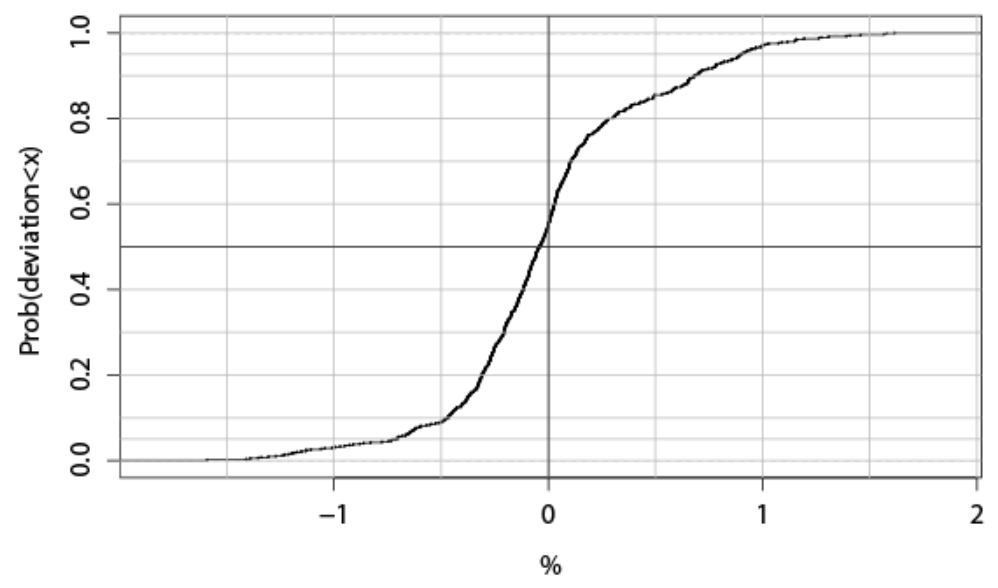

were large swings in trend inflation over that period, so it makes more sense to compare the hypothetical distribution to actual inflation in the inflation targeting period, which officially starts in January 2012. Over that period the volatility of 12-month inflation has actually been close to the volatility displayed in Figure 7: the 5th and 95th percentiles over this period are approximately -1.2 percent and 1.1 percent relative to the sample mean. Note however that these percentiles are based on a very short sample.

\section{Inflation-Targeting Era: Trading Off Inflation Target Misses and Price-Adjustment Costs}

The fact that the Federal Reserve's inflation target is 2 pecent instead of zero motivates an alternative notion of optimal inflation to the one used above. That alternative weights equally the inflation rate that minimizes adjustment costs and the 2 percent inflation target. The inflation rate that minimizes adjustment costs is close to zero on average, because there is no appreciable long-run trend in relative energy prices. Therefore, on average this alternative measure of optimal inflation will lie between 2 percent and zero. Figures 8 and 9 plot the implied inflation rate (measured in monthly and annual terms) over the period for 
Figure 8 Optimal Inflation, Trading Off Inflation Target and Price-Adjustment Costs

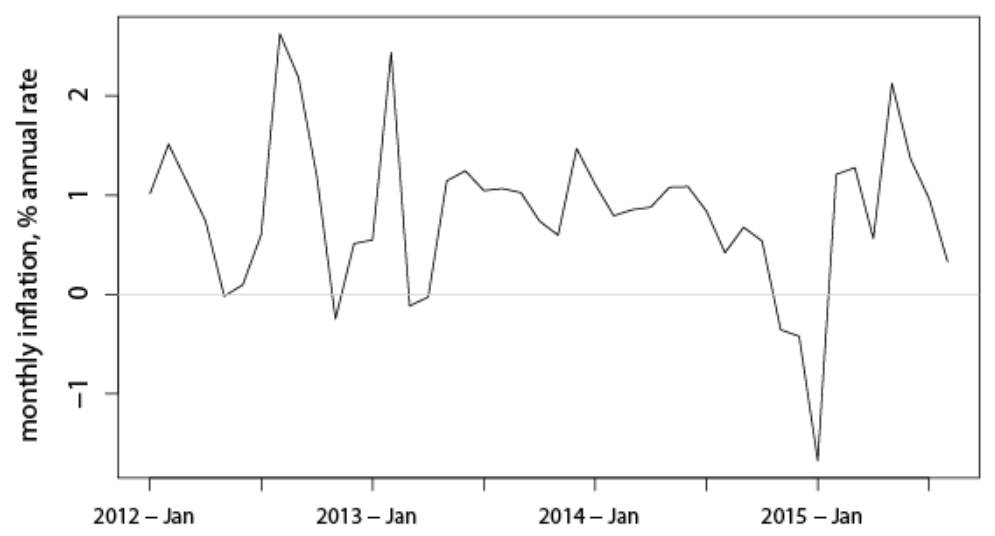

which the Federal Reserve has had a formal inflation target. The lines plotted in these figures are simply the average of 2 percent and the lines plotted in Figures 5 and 6. Thus, for the most recent period, instead of optimal deflation at around 1.25 percent, there is optimal inflation at around 0.4 percent. Actual 12-month inflation has been between 0.15 percent and 0.35 percent throughout 2015 .

\section{Inflation-Targeting Era: Trade-off When Adjustment Costs are Relative to 2 Percent Price Increase}

The fact that there is little long-run trend in relative energy price means that the measure of optimal inflation in Figures 8 and 9 is biased away from the Fed's official 2 percent inflation target. One might find this property problematic: Given that the Federal Open Market Committee has stated its intention to keep inflation around 2 percent, there are limits to the immediate practical usefulness of a prescription that the Fed keep average inflation below 2 percent. To address that concern, here we modify the optimal inflation measure from Figures 8 and 9 by positing that the costs of price adjustment are incurred relative to a 2 percent change in prices rather than relative to no change in prices. 
Figure 9 Optimal Monthly Inflation, Measured Over 12 Months, Trading Off Inflation Target and Price-Adjustment Costs

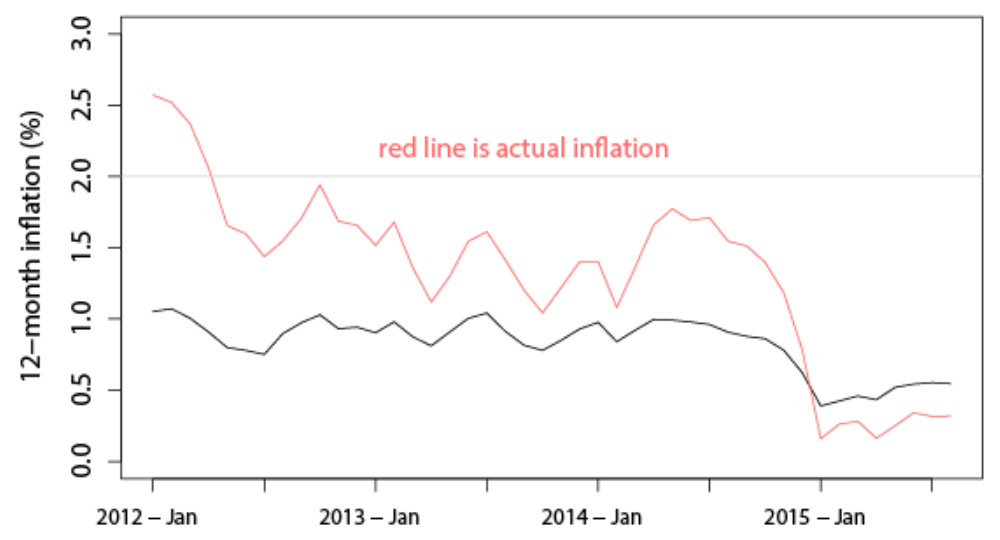

That is, instead of (15) we use

$$
\xi_{k, t}(z)=\frac{\theta_{k}}{2}\left(\frac{y_{k, t}(z)}{a_{k, t}}\right)\left(\frac{P_{k, t}(z)}{P_{k, t-1}(z)}-(1.02)^{1 / 12}\right)^{2} .
$$

With this modification, the inflation rate that minimizes adjustment costs will be 2 percent on average unless there is a trend in relative prices. The assumption behind (34) is not entirely ad hoc. In a world with expectations anchored at 2 percent inflation, it seems plausible that households and firms would adapt so that there would eventually be negligible costs associated with prices changing at a 2 percent rate.

Figures 10 and 11 plot the modified-optimal inflation rate that is a simple average of 2 percent and the inflation rate that minimizes sector 2 price-adjustment costs when those costs are incurred relative to a 2 percent trend. Focusing on Figure 11, the 12-month inflation rate, two features stand out. First, as expected, the optimal inflation rate in 2015 rises relative to what the previous figures showed; it is currently around 1.5 percent, which is well above the actual inflation rate, indicated by the red line in the figure. Second, although the fluctuations have been small, since 2012 the optimal inflation rate has been persistently below 2 percent, even though both components of the calculation tie that rate 
Figure 10 Optimal Inflation, Trading Off 2 Percent Target and Price-Adjustment Costs Relative to 2 Percent

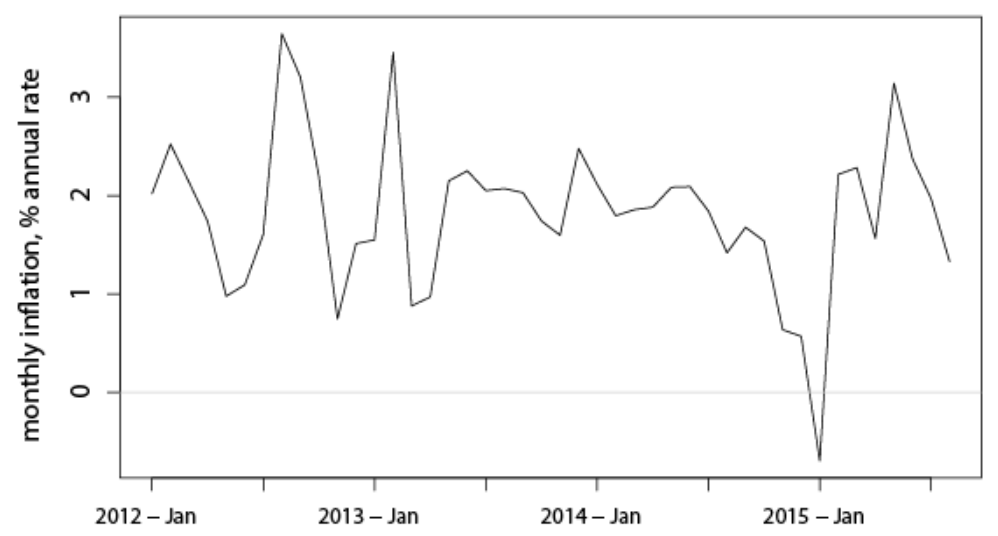

to 2 percent over the long run. The obvious explanation is that since 2012 there have been repeated large declines in relative energy prices.

For Figure 12, we plot a second version of optimal inflation that is centered around 2 percent. In this case the optimality criterion puts full weight on minimizing adjustment costs relative to a 2 percent rate of price change. Because no weight is placed on achieving the 2 percent inflation target in a given period, optimal inflation declines more in early 2015 than when the 2 percent inflation target receives equal weight, in Figure 11. It is still the case, however, that the optimal inflation rate in Figure 11 has been above actual inflation in recent years.

\section{CONCLUSION AND CAVEATS}

While monetary policy's goals are typically framed in terms of aggregate inflation, the aggregate inflation rate is an outcome of many individual price changes. Relative prices across goods and sectors undergo long-run trend changes and dramatic monthly fluctuations. How those factors affect the optimal inflation rate has been our focus. With respect to long-run trends, we used a particular model with costly price adjustment to show how the optimal inflation rate can vary with 
Figure 11 Optimal Monthly Inflation, Measured Over 12 Months, Trading Off 2 Percent Target and Adjustment Costs Relative to 2 Percent

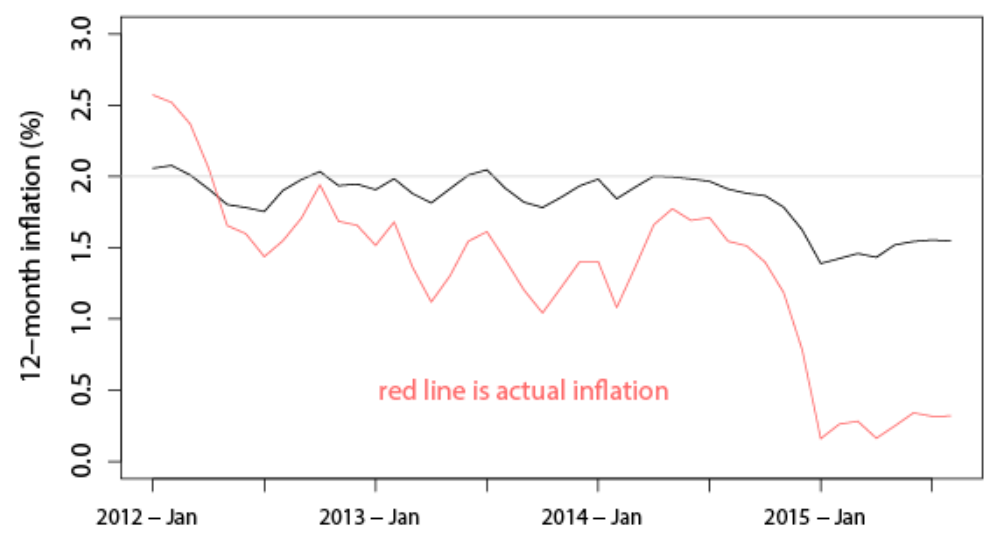

relative productivity growth across sectors and relative price-adjustment costs. With respect to short-run fluctuations, we narrowed the analysis to the behavior of relative energy prices in the United States, tracing out measures of the inflation rate over time that would have minimized price-adjustment costs according to the model. The stark nature of the model means that the results on steady-state inflation should be viewed as suggestive rather than definitive. However, the qualitative result that deflation (inflation) is optimal when price stickiness is relatively high in sectors that have relatively low (high) productivity growth is somewhat general, having also been shown to hold in models of staggered price setting and fixed costs of price adjustment (Wolman 2011). The results on period-by-period inflation may be of more practical use because they do not rely on the entire model and they emphasize the relative price behavior of the most volatile component of the consumption price index, energy goods and services. In line with Aoki (2001), we found that the dramatic decline in energy prices in 2015 was associated with a marked decline in the optimal inflation rate, even when the optimality criterion put a weight of one-half on meeting the 2 percent inflation target. 
Figure 12 Optimal Monthly Inflation, Measured Over 12 Months, Adjustment Costs Relative to 2 Percent

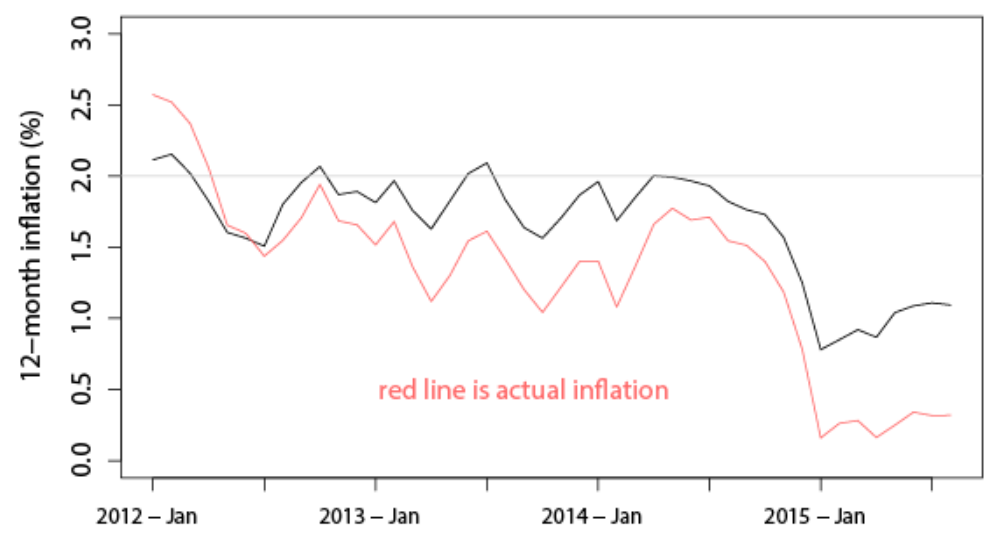

Throughout the paper, relative price changes were viewed as exogenous; in the steady-state analysis relative price changes were generated by exogenous differences in productivity growth across sectors, whereas in the short-run analysis relative price changes themselves were taken directly as inputs into the determination of optimal policy. Of course, any mechanism for monetary nonneutrality will generally lead to relative price changes being in part endogenous with respect to monetary policy. Given our ignorance about the details of that endogeneity however, proceeding under the assumption that relative price changes are exogenous seems like a reasonable way to proceed, although certainly not the only reasonable way. For simplicity, and in order to focus attention on the behavior of energy prices, the model in this paper had only two sectors, whereas the number of consumption categories measured by the Bureau of Economic Analysis is in the hundreds. In principle, one could perform the same kind of analysis in a model with many more sectors.

Throughout the paper, we assumed that monetary policy could directly control the inflation rate. For analyzing long-run trends this assumption seems appropriate, but in the shorter run it is clearly problematic. Any discussion of monetary policy and the behavior of inflation in 2014 and 2015 needs to confront the question of how accurately 
and over what horizon a central bank can control inflation. Here it was simply assumed that the central bank has perfect control, and optimal inflation was derived under that assumption. Perfect control is an important benchmark. With imperfect control, large relative price shocks will likely lead to greater fluctuations in the optimal inflation rate. That perspective suggests that optimal inflation in 2015 may have been below the levels in Figures 11 and 12. This is clearly a topic on which further work is needed.

APPENDIX: STEADY-STATE WELFARE EXPRESSION

In this Appendix we derive the closed-form solution for steady-state welfare, used to produce Figures 1-4. From (25)-(29), we have

$$
\begin{aligned}
p_{1,0} & =\frac{\varepsilon}{(\varepsilon-1)(1+\tau)} w_{0} \Gamma_{1}(\pi) \\
p_{2,0} & =\frac{\varepsilon}{(\varepsilon-1)(1+\tau)} w_{0} \Gamma_{2}(\pi) \\
\frac{p_{2,0}}{1-\nu} & =\left(\frac{1-\nu}{\nu} \frac{p_{1,0}}{p_{2,0}}\right)^{-\nu}
\end{aligned}
$$

where

$$
\begin{gathered}
\Gamma_{1}(\pi)=1-\theta_{1}\left(\left(\frac{\mu_{1}}{\mu_{2}}\right)^{\nu-1} \pi-1\right) \times \\
{\left[\left(\frac{1-\beta}{\varepsilon}\right)\left(\frac{\mu_{1}}{\mu_{2}}\right)^{\nu-1} \pi-\frac{1}{2}\left(\left(\frac{\mu_{1}}{\mu_{2}}\right)^{\nu-1} \pi-1\right)\right]}
\end{gathered}
$$

and

$$
\begin{gathered}
\Gamma_{2}(\pi)=1-\theta_{2}\left(\left(\frac{\mu_{1}}{\mu_{2}}\right)^{-\nu} \pi-1\right) \times \\
{\left[\left(\frac{1-\beta}{\varepsilon}\right)\left(\frac{\mu_{1}}{\mu_{2}}\right)^{-\nu} \pi-\frac{1}{2}\left(\left(\frac{\mu_{1}}{\mu_{2}}\right)^{-\nu} \pi-1\right)\right] .}
\end{gathered}
$$

It follows that

$$
\frac{p_{1,0}}{p_{2,0}}=\Gamma_{1}(\pi) / \Gamma_{2}(\pi) .
$$

We can then solve for $p_{1,0}, p_{2,0}$, and $w_{0}$ :

$$
p_{2,0}(\pi)=(1-\nu)\left(\frac{1-\nu}{\nu} \Gamma_{1}(\pi) / \Gamma_{2}(\pi)\right)^{-\nu},
$$




$$
w_{0}(\pi)=\frac{(\varepsilon-1)(1+\tau)}{\varepsilon}\left(\frac{\Gamma_{1}(\pi)}{\nu}\right)^{-\nu}\left(\frac{\Gamma_{2}(\pi)}{1-\nu}\right)^{\nu-1}
$$

and

$$
p_{1,0}(\pi)=(1-\nu)\left(\frac{1-\nu}{\nu}\right)^{-\nu}\left(\Gamma_{1}(\pi) / \Gamma_{2}(\pi)\right)^{1-\nu} .
$$

Consumption follows from (4) and (5):

$$
c_{0}(\pi)=\frac{(\varepsilon-1)(1+\tau)}{\varepsilon \chi}\left(\frac{\Gamma_{1}(\pi)}{\nu}\right)^{-\nu}\left(\frac{\Gamma_{2}(\pi)}{1-\nu}\right)^{\nu-1} .
$$

The last variable we need in order to compute welfare is labor input. From (18), we have

$$
h_{0}=\frac{y_{1,0}}{a_{1,0}} \cdot\left(1+\frac{\theta_{1}}{2}\left(\pi_{1}-1\right)^{2}\right)+\frac{y_{2,0}}{a_{2,0}} \cdot\left(1+\frac{\theta_{2}}{2}\left(\pi_{2,0}-1\right)^{2}\right) .
$$

This expression requires that we know $y_{1,0}$ and $y_{2,0}$. From (21) and (22), we can easily compute $y_{1,0}$ and $y_{2,0}$ using our solutions for the wage and relative prices:

$$
\begin{aligned}
y_{1,0}(\pi) & =\frac{\nu}{\chi} \frac{w_{0}(\pi)}{p_{1,0}(\pi)}, \\
y_{2,0}(\pi) & =\frac{1-\nu}{\chi} \frac{w_{0}(\pi)}{p_{2,0}(\pi)} .
\end{aligned}
$$

Then using (42) to compute labor input, we can evaluate welfare as a function of inflation:

$$
\begin{aligned}
W(\pi) & =\sum_{t=0}^{\infty} \beta^{t}\left(\ln c_{t}-\chi h_{0}\right) \\
& =\sum_{t=0}^{\infty} \beta^{t}\left(\ln c_{0}(\pi)+t \ln \left(\mu_{1}^{\nu} \mu_{2}^{1-\nu}\right)-\chi h_{0}(\pi)\right) .
\end{aligned}
$$

\section{REFERENCES}

Aoki, Kosuke. 2001. "Optimal Monetary Policy Responses to Relative-Price Changes." Journal of Monetary Economics 48 (August): 55-80.

Bils, Mark, and Peter J. Klenow. 2004. "On the Importance of Sticky Prices." Journal of Political Economy 112 (October): 947-85. 
Bodenstein, Martin, Christopher J. Erceg, and Luca Guerrieri. 2008. "Optimal Monetary Policy with Distinct Core and Headline Inflation Rates." Journal of Monetary Economics 55 (October): S18-S33.

Calvo, Guillermo A. 1983. "Staggered Prices in a Utility-Maximizing Framework." Journal of Monetary Economics 12 (September): 383-98.

Friedman, Milton. 1969. "The Optimum Quantity of Money." In The Optimum Quantity of Money and Other Essays, edited by Milton Friedman. Chicago: Aldine Publishing Company, 2-50.

Levy, Daniel, Mark Bergen, Shantanu Dutta, and Robert Venable. 1997. "The Magnitude of Menu Costs: Direct Evidence From Large U.S. Supermarket Chains." Quarterly Journal of Economics 112 (August): 791-825.

Rotemberg, Julio J. 1982. "Sticky Prices in the United States." Journal of Political Economy 90 (December): 1187-211.

Wolman, Alexander L. 2008. "Nominal Frictions, Relative Price Adjustment, and the Limits to Monetary Policy." Federal Reserve Bank of Richmond Economic Quarterly 94 (Summer): 219-33.

Wolman, Alexander L. 2011. "The Optimal Rate of Inflation with Trending Relative Prices." Journal of Money, Credit and Banking 43 (March-April): 355-84. 